\title{
Pharmacist's role in the system of palliative and hospice care in Ukraine and Poland
}

\author{
Sofiya Prokip', Iga Pawłowska², Bohdan Hromovyk ${ }^{3}$, Leszek Pawłowski ${ }^{4}$ \\ ${ }^{1}$ Department of Organization and Economics of Pharmacy, Pharmaceutical Faculty, Danylo Halytskyi Lviv National \\ Medical University, Ukraine \\ ${ }^{2}$ Chair and the Department of Pharmacology, Medical University of Gdańsk, Poland \\ ${ }^{3}$ Head of the Department of Organization and Economics of Pharmacy, Dean of the Pharmaceutical Faculty, Danylo \\ Halytskyi Lviv National Medical University, Ukraine \\ ${ }^{4}$ Department of Palliative Medicine, Medical University of Gdańsk, Poland
}

\section{ABSTRACT}

Introduction. The efficient pharmacotherapy is an important part of palliative and hospice care, and requires a multidisciplinary approach to the patients. The pharmacist, as the member of the multidisciplinary therapeutic team, is responsible for performing pharmaceutical care, which provides safe and efficient treatment. The aim of the research was to conduct a comparative research about the status of palliative and hospice care and role of the pharmacist (clinical pharmacist) in Ukraine and Poland.

Material and methods. It was a questionnaire survey conducted in Ukraine, as well as analysis of information sources associated with this subject. The questionnaire was developed on the basis of similar study conducted in Poland. It consisted of 15 multiple-choice questions addressed to head physicians and doctors in Ukraine. The obtained results were compared to the results of the mentioned above Polish study.

Results. Eight head physicians and 22 doctors (30 questionnaires) from 13 palliative and hospice care institutions in Ukraine responded to the survey. It has been found that almost half in Ukraine (43\%) believed that the pharmacist should be a mandatory member of a multidisciplinary team, because of his/her significant role in drug management in hospice.

Conclusion. A multidisciplinary approach to satisfying of patients' needs in palliative and hospice care has a great significance. Results of the study testify to the importance of including the pharmacists into the multidisciplinary team.

Keywords: palliative care, pharmacist, drug therapy, pharmaceutical care.

\section{Introduction}

Since the $80^{\prime}$ s of the $20^{\text {th }}$ century, due to the biopsychosocial approach formation of a multidisciplinary approach to the provision of services was developed. This fact caused involvement as wide as possible of the range of professionals in order to solve problems of patient and his/her family. The basis of this approach is the statement, that body, mind, emotions and spirit are dynamically correlated in each person, and changes in one of these components affect changes in all others. That is why representatives from different specialties are working in multidisciplinary teams and their work promotes a comprehensive ensuring of patients' needs [1].

Because the palliative patients and their families need comprehensive support, that will maximally take into account their needs, in 1978 the World Health Organization (WHO) stated the need for multidisciplinary collaboration for successful provision of palliative and hospice care (PHC) to the patients. 
The multidisciplinary team

Summary results of international studies have led to the conclusion, that the multidisciplinary team in the PHC should include four groups of employees: 1) specialists in palliative care (doctors, nurses); 2) allied health professionals (pharmacist, therapist, physiotherapist, dietician, psychologist, spiritual carers of various denominations, lawyers, social workers); 3) complementary therapists (art therapist, music therapist, massage therapist); 4) other staff (administrative staff, etc.) [7,10]. Moreover, volunteers, who support the professional staff in the care of patients, play an important role in PHC. They are members of multidisciplinary therapeutic team and perform various tasks, which help patients and their families [11].

The rational pharmacotherapy (PT) is a separate, socially important segment of $\mathrm{PHC}$, which requires significant financial and organizational resources. One of the ways to optimize the efficiency of PT is the provision of pharmaceutical care to patients. It can be carried out by pharmacist in a pharmacy, which collaborates or is located directly in a hospice or in other pharmacies, when pharmaceutical care is directed to palliative patients and their family members.

\section{The status of PHC in Ukraine}

Pursuant to statistical data of the Association of Palliative and Hospice Care (APHC) over the last five years the number of deaths in Ukraine is about 800,000 people per year. According to $\mathrm{WHO}$ recommendations at least 500,000 end-of-life patients and nearly 2 million members of their families in Ukraine need supportive care every year [2].

Basic health care establishments, which provide palliative care in Ukraine, are hospices, palliative care departments in multi-profile hospitals and hospitals of oncological, tuberculosis and geriatric profile, and also HIV/AIDS centers. Inpatient PHC institutions provide medical care and elements of psychological and spiritual support. However, it should be noted that most people do not have access to comprehensive PHC.

The first hospices in Ukraine were established in Lviv, Korosten' and Ivano-Frankivsk in 1996-1997. In accordance with the data of APHC there are 5 inpatient hospices and 13 palliative care departments, which have 521 inpatient beds, and 7 HIV/AIDS centers (up to 50 beds) in Ukraine as of January 1, 2013. Also 3 PHC institutions (about 65 inpatient beds) are charitable, and the local health authorities are their co-founders. Bed capacity covers only about $20 \%$ of demands for inpatient hospice care (at a rate of 10 beds for pal- liative patients per 100 thousand population, that is 4,600 beds for Ukraine). Thus PHC is mainly administered at home by relatives or carers of patients. These data have shown a significant deficiency of specialized medical institutions for providing PHC to patients and psychological support of their families after the loss of loved ones [3, 4].

Conformably to hospice pharmacy and the role of pharmacists in the PHC system of Ukraine pharmacist's (CP) position is not included in the staffing table of establishments such as "Hospice" (Annex 50 to the Order of Ministry of Health of Ukraine "On the staff standards and typical staffing tables of health care facilities" from 23.02.2000 N 33). Only a small amount of institutions and departments of PHC in Ukraine cooperate with pharmacists (CP) (preferably in multi-profile hospitals). Therefore, pharmaceutical care is provided by pharmacists (CP) in hospital pharmacies or other pharmacies during the dispensing drugs to patients or their carers.

\section{The status of PHC in Poland}

$\mathrm{PHC}$ in Poland is provided in 476 various units, including 321 home hospices and 137 inpatient units (residential hospices and hospital-based palliative medicine wards) and others. There are 2232 palliative care beds, what is 58.3 per million inhabitants. Most of them were established by Catholic Church and nongovernmental organizations (associations and foundations). PHC is provided for patients with incurable diseases, like cancer, as well as for patients with heart failure, respiratory disorders, wounds and bedsores. The services are regulated by law and financed from public health care system $[5,6]$.

Hospice staff consists of professionals, e.g. physicians, nurses, psychologists, pharmacists, physiotherapists, priests and social workers. Nowadays, most of them are paid workers, but some perform their services as volunteers. Nevertheless, majority of volunteers do not carry out professional services and they support medical staff in patient care. Moreover, volunteers are engaged in other activates like charity and public collections. Physicians and nurses can participate in postgraduate education in palliative medicine.

According to the Polish Pharmaceutical law, pharmacists should be the members of hospice staff in the inpatient units. Residential hospices and hospital-based palliative medicine wards are obliged to establish hospital pharmacy and employ a master of pharmacy as a pharmacists team manager. It is associated with drug management and performing pharmaceutical services. 


\section{Aim}

The aim of the study was to evaluate the current status of hospice pharmacy in Ukraine and to compare the role of the pharmacist in hospice and palliative care in Ukraine to that in Poland.

\section{Methods}

Questionnaire survey, analysis of literature associated with examined issues, systemic analysis was used as methods for the assessment of pharmacist's role in PHC.

The questionnaire developed on the basis on similar study conducted in Poland, contained 15 multiple-choice items, and has been adopted for survey in Ukraine [12]. It consisted of three parts: the first contained questions concerning information about the respondents (age, position, profession); the second was devoted to the basic characteristics of PHC institution (number of beds, funding, drugs and commodities supply, presence of pharmacist (clinical pharmacist - CP in the staff, etc.); the third was dedicated to the duties and tasks that pharmacist (CP) can perform in a hospice, possible cooperation with doctors and advantages of including pharmacist (CP) in the multidisciplinary hospice team.

Because of pharmacist's (CP) absence in staffing table of PHC establishments in Ukraine, a questionnaire was designed to survey head physicians and doctors of hospices and palliative care departments.

Data obtained from Ukraine was compared to the similar study previously conducted in Poland, which was published in Polish scientific journal on palliative medicine [12].

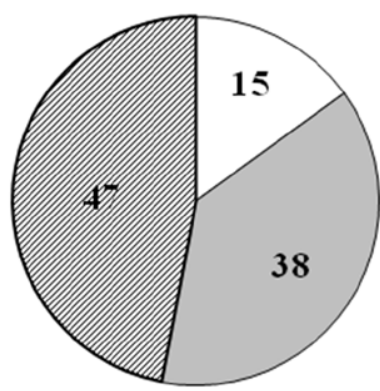

$<10$ beds
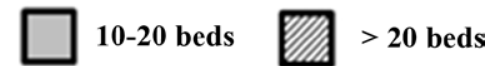

Figure 1. The number of inpatient beds in PHC institutions in Ukraine

\section{Results}

As a result of the study, conducted in Ukraine, 8 head physicians and 22 doctors (30 questionnaires) from 13 $\mathrm{PHC}$ institutions responded to the survey.

It has been found, that the number of inpatient beds in almost half of the establishments in Ukraine was more than 20 beds, and almost two-fifths - with number of beds from 10 to 20 (Figure 1).

Suppliers of medicines for PHC establishments in Ukraine are primarily community pharmacies, pharmaceutical warehouses or wholesale pharmaceutical companies (Figure 2). Only 27\% of respondents answered that institutions are partially supplied with medicines by pharmacies, which are located in them (usually in multi-profile hospitals). Among other sources the respondents indicated charitable organizations, local authorities and relatives of patients (presented percentages do not add up to $100 \%$, because of the multiplechoice question).

Most respondents in their answers indicated a nurse as a person responsible for supply the hospice with drugs (Figure 3). Ukrainian respondents did not indicate a pharmacist as the responsible person for provision with medicines. Among other persons, responsible for supply of medicines, respondents indicated the relatives of patients.

Among the tasks that a pharmacist should perform in hospice the searching for domestic analogues and comparative assessment of their value were the most often met in answers of Ukrainian respondents (Figure 4). Also other functions were marked: tracking changes in legislation, appearance of new medicines; providing information about drugs; incoming control, account-

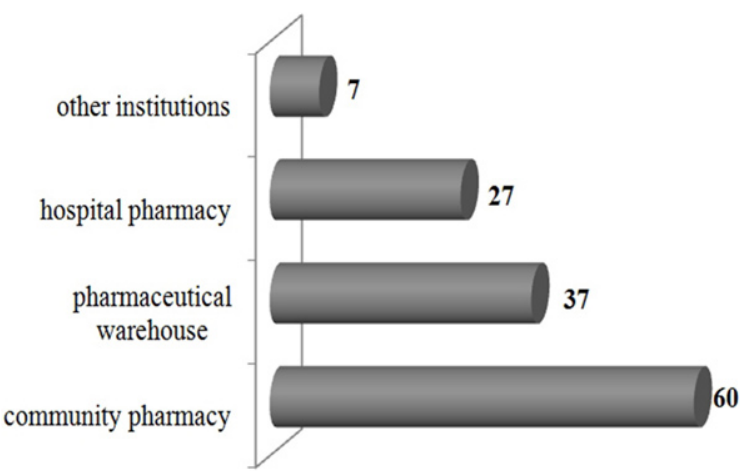

Figure 2. Organizations, which provide Ukrainian PHC institutions with drugs (\%) 


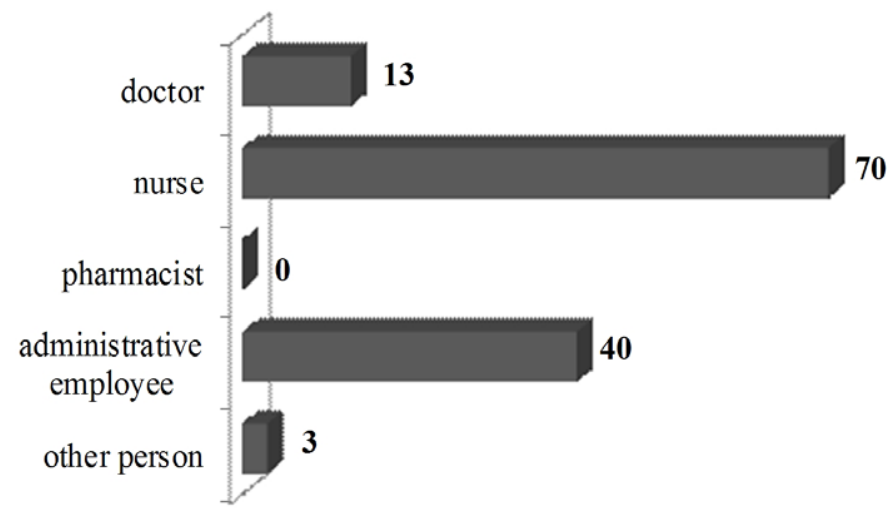

Figure 3. Persons, responsible for supply of the establishment with drugs (\%)

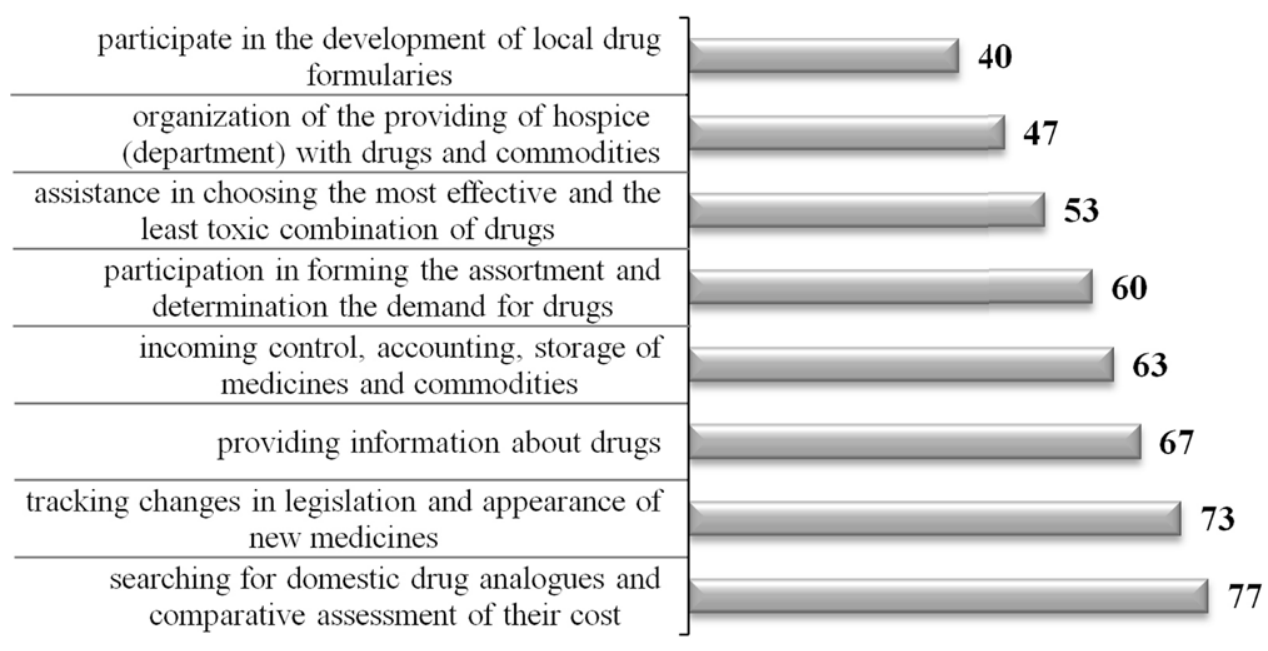

Figure 4. Tasks that a pharmacist should perform in hospice in Ukraine (\% of respondents)

ing, storage of medicines and commodities; participation in forming the assortment and determination the demand for drugs.

\section{Discussion}

\section{Comparison of surveys}

The survey showed that there is no position of pharmacist in inpatient hospices and palliative care departments in Ukraine. Contrary, in Poland pharmacists are working in half of inpatient hospices. Polish hospices employ usually no more than one pharmacist [12].

In Ukraine, only one fifth of physicians (20\%) indicated the cooperation with pharmacists and the others do not cooperate with them. By contrast, in Poland in more than $40 \%$ of hospices the pharmacist consults the members of therapeutic team [12].

Polish Pharmaceutical law provides two types of departments in health care institutions, in which pharmaceutical services are performed. The first one is hospital pharmacy, and the second - hospital pharmacy department. On the other hand, in home hospices patients buy medicines prescribed by hospice physicians in community pharmacies. In practice, only hospital pharmacy departments are present in residential hospices, and the most of PHC units have no specific department in which pharmaceutical services are performed [12]. Only $27 \%$ of Ukrainian respondents answered that institutions are partially supplied with medicines by pharmacies.

Three-quarters of Polish hospice directors and less than a half $(43 \%)$ of Ukrainian respondents affirmatively answered to the question "Should the pharmacist be a mandatory member of a multidisciplinary team?" This difference is due to the distinctions in pharmaceutical legislation and staffing tables of PHC establishments in both countries.

In both countries not a pharmacist but a nurse is the person responsible for supply the hospice of drugs [12].

In Ukraine a pharmacist should perform the following tasks in hospice: the searching for domestic analogues, comparative assessment of their value 


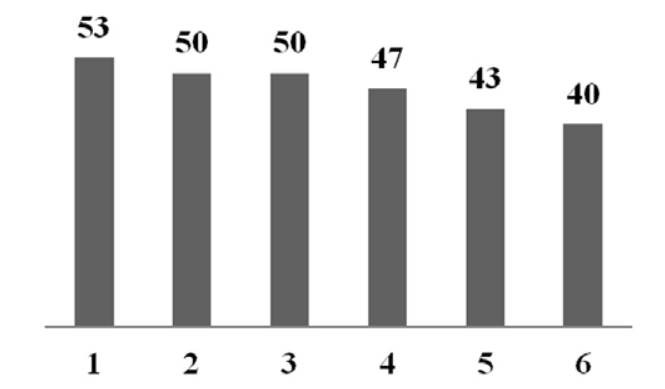

\begin{tabular}{c|l}
\hline 1 & supply hospice of medicines \\
\hline 2 & monitirong of PT \\
\hline 3 & $\begin{array}{l}\text { providing of the procedure of } \\
\text { incoming control and proper storage } \\
\text { of medicines }\end{array}$ \\
\hline 4 & introduction of new drugs in PT \\
\hline 5 & decrease the cost of PT \\
\hline 6 & promoting of natient-centered PT
\end{tabular}

Figure 5. Advantages of presence a pharmacist in hospice in Ukraine (\%)

etc. In comparison, in Poland hospice pharmacists are engaged in carrying out such activities as: giving information about drugs, their ordering and dispensing as well as providing training for hospice staff [12].

Respondents in both countries consider that the main advantages of presence a pharmacist in hospice are: improving of supply of drugs, providing the documentation of opioid and psychotropic drugs management, the procedure of incoming control, accounting, dispensing and proper storage of medicines, decreasing the cost of PT (Figure 5) [12].

Therefore, a multidisciplinary approach to the comprehensive satisfying of patients' needs in PHC has a great importance. Thus, the participation of pharmacists (CP) in PHC is integral and important part of it, and the results of the study testify to the importance of their inclusion in the multidisciplinary team.

\section{Conclusion}

The results of analysis of PHC status in Ukraine and in Poland suggest a lower level of availability of inpatient palliative care for the population in Ukraine than in Poland. Since a multidisciplinary approach for successful provision of PHC to the patients has a great importance, the participation and inclusion of pharmacists (CP) in multidisciplinary team is extremely relevant. As a result of questionnaire survey it has been found that pharmacists work in half of the studied hospices in Poland, and that the position of a pharmacist in Ukrainian PHC institutions is absent. In Poland there are legal and organizational constrains to including the pharmacists in PHC and for residential hospices and in hospital-based palliative medicine wards it is obligatory. Three-quarters of respondents in Poland and almost half in Ukraine believed that the pharmacist should be a mandatory member of multidisciplinary team. The advantages of presence of a pharmacist in the PHC institution, as the respondents of both countries consider, were the following: improvement of supplying the hospice with drugs, organizing incoming control, accounting, storage of medicines and decreasing the cost of pharmacotherapy.

\section{Acknowledgements}

\section{Conflict of interest statement}

The authors declare that there is no conflict of interest in the authorship or publication of contribution.

\section{Funding sources}

There are no sources of funding to declare.

\section{References}

1. Volf OO. Multidisciplinary approach to the comprehensive meet the needs of patients during the rendering of palliative and hospice care in the context of family medicine. Available at: http://www.palliativ.kiev.ua/index. php?item=articles\&id=4. Accessed 07-05-2013.

2. Volf OO. Comprehensive meet the needs of terminally ill at the end of life as an important aspect of humanization in the sphere of social policy. Available at:http://www. palliativ.kiev.ua/index.php?item=articles\&id=7. Accessed 04-05-2013.

3. Information about the overall status of palliative and hospice care in Ukraine. Available at: http://www.palliativ.kiev.ua/. Accessed 25-05-2013.

4. Tsarenko AV. Development of the Chapter "Palliative Care" of the State Program "Health 2020: Ukrainian dimension". Available at: http://ligalife.com.ua/k/1/6_ Carenko.pdf. Accessed 14-05-2013.

5. Cialkowska-Rysz A. The situation and chalenges of palliative care in Poland. Medycyna Paliatywna. 2009;1: 22-26.

6. Centeno C, Pons JJ, Lynch T, Donea O, Rocafort J, Clark D. EAPC Atlas of Palliative Care in Europe 2013 - Cartographic Edition. Milan: EAPC Press; 2013.

7. Crawford GB, Price SD. Team working: palliative care as a model of interdisciplinary practice. Med J Aust. 2003;179:32-34.

8. Groom J. Palliative Care Spirituality \& the Multidisciplinary Team. Melbourne Citymission Palliative Care (10 November 2010). Available at: http://www.hccvi.org.au. Accessed 10-05-2013.

9. Hancock MJ. The Multidisciplinary Team and Palliative Care: Lessons from the "Retirement Capital of Canada". Summer Work Experience and Training Program, May to August, 2010. Available at: http://www.umanitoba.ca/ 
faculties/medicine/family_medicine/media/Killarney. Hancock.2010.pdf. Accessed 14-04-2013.

10. Spruyt O. Team networking in palliative care. Indian J Palliat Care. 2011;1:17-19.

11. Harris MD, Olson JM. Volunteers as members of the home healthcare and hospice teams. Home Health Nurse. 1998;16(5):289-293.

12. Pawlowska I, Pawlowski L, Lichodziejewska-Niemierko M. Pharmacist's role and his activities in residential hospice on the basis on preliminary study. Med Paliat. 2012;2:80-89.
Acceptance for editing: 2014-12-10 Acceptance for publication: 2014-12-31

\section{Correspondence address:} Sofiya Prokip

69 Pekarska Street, 79010 Lviv, Ukraine phone: +3803222768639 email: sofiyaprokip@gmail.com 